ARTICLE

Received 6 Oct 2014 | Accepted 18 Feb 2015 | Published 5 May $2015 \quad$ DOl: 10.1038/ncomms7681

\title{
Crossreactivity to vinculin and microbes provides a molecular basis for HLA-based protection against rheumatoid arthritis
}

Jurgen van Heemst ${ }^{1}{ }^{\star}$, Diahann T. S. L. Jansen ${ }^{1, \star}$, Savvas Polydorides ${ }^{2}$, Antonis K. Moustakas ${ }^{3}$, Marieke Bax ${ }^{1}$, Anouk L. Feitsma ${ }^{1}$, Diënne G. Bontrop-Elferink ${ }^{4}$, Martine Baarse ${ }^{1}$, Diane van der Woude ${ }^{1}$, Gert-Jan Wolbink ${ }^{5}$, Theo Rispens ${ }^{5}$, Frits Koning ${ }^{4}$, René R. P. de Vries ${ }^{4}$, George K. Papadopoulos ${ }^{6}$, Georgios Archontis ${ }^{2}$, Tom W. Huizinga ${ }^{1} \&$ René E. Toes ${ }^{1}$

The HLA locus is the strongest risk factor for anti-citrullinated protein antibody (ACPA) ${ }^{+}$ rheumatoid arthritis (RA). Despite considerable efforts in the last 35 years, this association is poorly understood. Here we identify (citrullinated) vinculin, present in the joints of ACPA ${ }^{+}$ RA patients, as an autoantigen targeted by ACPA and CD4 ${ }^{+} \mathrm{T}$ cells. These $\mathrm{T}$ cells recognize an epitope with the core sequence DERAA, which is also found in many microbes and in protective HLA-DRB1*13 molecules, presented by predisposing HLA-DQ molecules. Moreover, these $T$ cells crossreact with vinculin-derived and microbial-derived DERAA epitopes. Intriguingly, DERAA-directed T cells are not detected in HLA-DRB1*13 ${ }^{+}$donors, indicating that the DERAA epitope from HLA-DRB1*13 mediates (thymic) tolerance in these donors and explaining the protective effects associated with HLA-DRB1*13. Together our data indicate the involvement of pathogen-induced DERAA-directed T cells in the HLA-RA association and provide a molecular basis for the contribution of protective/predisposing HLA alleles.

\footnotetext{
${ }^{1}$ Department of Rheumatology, Leiden University Medical Center, 2300 RC Leiden, The Netherlands. ${ }^{2}$ Department of Physics, University of Cyprus, 2109 Nicosia, Cyprus. ${ }^{3}$ Faculty of Agricultural Technology, Technological Educational Institute of loanian Islands, Argostoli, Cephallonia 28100, Greece.

${ }^{4}$ Department of Immunohematology and Bloodtransfusion, Leiden University Medical Center, 2300 RC Leiden, The Netherlands. ${ }^{5}$ Sanquin Research and Landsteiner Laboratory, Academic Medical Center, 1066 CX Amsterdam, The Netherlands. ${ }^{6}$ Laboratory of Biochemistry and Biophysics, Faculty of Agricultural Technology, Epirus Institute of Technology, Arta 47100, Greece. ${ }^{*}$ These authors contributed equally to this work. Correspondence and requests for materials should be addressed to R.E.T. (email: r.e.m.toes@lumc.nl).
} 
R heumatoid arthritis (RA) is a chronic autoimmune disease affecting synovial joints that can lead to severe disability. Pivotal pathophysiological insight has been obtained by the identification of anti-citrullinated protein antibodies $(\mathrm{ACPA})^{1,2}$. These autoantibodies target proteins that have undergone a posttranslational conversion of arginine to citrulline, catalysed by peptidylarginine deiminases (PAD enzymes) ${ }^{3}$. ACPA are highly specific for RA, enriched in the joints of patients and can crossreact between citrullinated antigens that are expressed in the inflamed joints ${ }^{4-8}$. It is clear now that RA represents two main syndromes, $\mathrm{ACPA}^{+}$and $\mathrm{ACPA}^{-}$disease, each with distinct genetic and environmental risk factors and disease outcome ${ }^{9-12}$. Characteristics of ACPA (for example, isotype usage and epitope spreading) indicate the involvement of $\mathrm{CD} 4{ }^{+} \mathrm{T}$ cell help in shaping the ACPA response ${ }^{13}$.

The most important genetic risk factor for $\mathrm{ACPA}^{+} \mathrm{RA}$ is the HLA class II locus and risk is confined to a region with genes encoding for the beta chain of HLA-DR and the alpha and beta chain of HLA-DQ that are in tight linkage disequilibrium (LD) and inherited in haplotypes ${ }^{14,15}$. An understanding of the HLA class II association and the relative contribution of the HLA-DR and HLA-DQ locus has been lacking for the last 35 years.

Next to the association of the predisposing alleles to $\mathrm{ACPA}^{+}$ RA, other HLA molecules are associated with protection. These protective HLA alleles, mainly HLA-DRB1* 13 , carry the five amino-acid sequence DERAA at positions 70-74 of the beta chain and protect also in the presence of predisposing alleles ${ }^{16,17}$. Intriguingly, protection by these alleles is transferred from mother to child, supporting an active protective role of these alleles, possibly via microchimeric cells influencing thymic selection of $\mathrm{CD}^{+} \mathrm{T}$ cells, and indicating a dominant role of HLA-DRB $1^{\star} 13$ in disease protection ${ }^{18}$.

HLA-derived peptides are a dominant peptide source presented by HLA class II molecules. We therefore proposed that the protective effect of HLA-DRB $1^{\star} 13$ is explained by presentation of an $\mathrm{HLA}_{-\mathrm{DRB}}{ }^{\star} 13$-derived peptide in the context of other (predisposing) HLA class II molecules ${ }^{19-21}$.

It was previously shown that the degradation of HLA-DRB1 ${ }^{\star} 13$ can result in the presentation of a peptide with the core sequence DERAA by other HLA class II molecules to CD4 ${ }^{+} \mathrm{T}$ cells ${ }^{22}$. This could allow for the negative selection of such 'DERAA-directed' $\mathrm{CD}^{+}$thymocytes. Interestingly, the DERAA sequence is also found in many microbes and in the self-protein vinculin. Vinculin is expressed in the synovium and was recently shown to be citrullinated in the synovial fluid of an RA patient ${ }^{4,23}$. Likewise, $\mathrm{T}$ cells directed to vinculin are found under certain infectious conditions, indicating that $\mathrm{T}$ cell tolerance to vinculin is not absolute ${ }^{24,25}$. Molecular mimicry of self-proteins with pathogenic proteins was proposed as an important mechanism to break $\mathrm{T}$ cell tolerance ${ }^{26,27}$. Therefore, we postulate that on priming of DERAA-directed $\mathrm{T}$ cells by microbes expressing DERAA-containing proteins, $\mathrm{T}$ cells crossreactive to vinculin would be able to provide help to $\mathrm{B}$ cells reactive to citrullinated vinculin. This would ultimately result in the production of ACPA. In HLA-DRB1 ${ }^{\star} 13$-positive donors, these $\mathrm{T}$ cells are conceivably deleted, leading to protection against $\mathrm{ACPA}^{+}$disease.

Here we show that citrullinated vinculin is novel autoantigen for ACPA antibodies. In addition, we demonstrate the presence of a $\mathrm{T}$ cell population in HLA-DRB1*13-negative donors that specifically recognize a DERAA-containing vinculin epitope and that crossreact with DERAA sequences derived from pathogens.

\section{Results}

Citrullinated vinculin is a novel target for ACPA. We speculate that the protective effects of HLA-DRB ${ }^{\star} 13$ on the development of $\mathrm{ACPA}^{+} \mathrm{RA}$ are related to a $\mathrm{T}$ cell response reactive to a sequence that is commonly present in the HLA-DRB1 ${ }^{\star} 13$ molecule, microorganisms and self-proteins that are targeted by ACPA. Indeed, a 5-amino-acid long HLA-DRB1*13-derived sequence (DERAA) is present in many microorganisms and a few self-proteins. Of these self-proteins, the citrullinated protein vinculin attracted our attention. Therefore, we first analysed whether citrullinated vinculin is recognized by ACPA. To this end, we citrullinated vinculin in vitro with $\mathrm{PAD}$ enzymes and tested both native and citrullinated vinculin for recognition with serum of an $\mathrm{ACPA}^{+} \mathrm{RA}$ patient. We observed citrulline-specific recognition of vinculin by serum of an $\mathrm{ACPA}^{+} \mathrm{RA}$ patient, but not with an $\mathrm{ACPA}^{-}$patient (Fig. 1a). We further confirmed that citrullinated vinculin is a target of ACPA using an ACPA monoclonal antibody (Fig. $1 \mathrm{~b})^{28}$

Recently, several reports showed the presence of citrullinated vinculin in the synovial fluid of $\mathrm{ACPA}^{+}$RA patients. In addition, three sites of in vivo citrullination on this protein were identified: Arg285, Arg622 and Arg823 (refs 4,23). When we studied antibody responses to these citrullination sites, we could show recognition by $34 \%$ of tested sera from $\mathrm{ACPA}^{+} \mathrm{RA}$ patients versus $5 \%$ of sera from $\mathrm{ACPA}^{-}$patients (Fig. 1c). Sera of $\mathrm{ACPA}^{+}$RA patients are highly (cross-)reactive towards multiple citrullinated antigens. Indeed, when we quantified responses to citrullinated alpha-enolase, fibrinogen, vimentin and myelin basic protein in patient sera that react to citrullinated vinculin peptides, we could readily demonstrate additional reactivities indicating

a
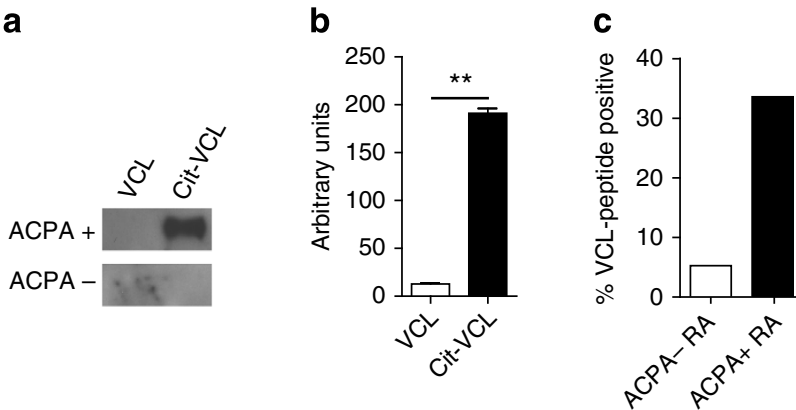

d

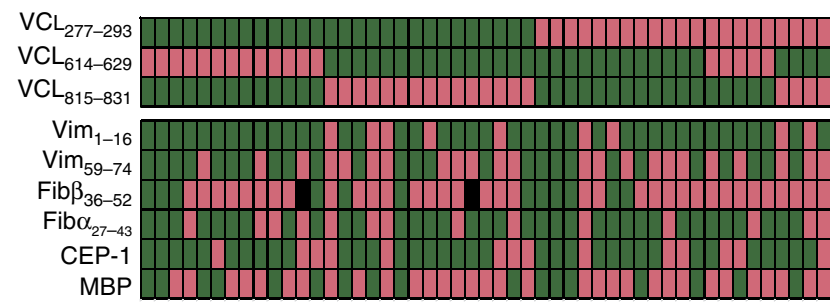

Figure 1 | Citrullinated vinculin is a novel autoantigen targeted by ACPA. (a) Western blot (Supplementary Fig. 22) of native and citrullinated vinculin protein, stained with the serum of an $\mathrm{ACPA}^{+}$or an ACPA ${ }^{-} \mathrm{RA}$ patient. (b) Enzyme-linked immunosorbent assay (ELISA) of vinculin- or citrullinated vinculin protein-coated plates stained with ACPA monoclonal antibody anti-citFib1.1. Two-sided statistical analysis was performed using a Student's t-test with ${ }^{* *}$ indicating $P<0.001$. Error bar is s.e.m. (c) ELISA of citrullinated vinculin peptides VCL-CIT285 $277-293$, VCL-CIT622 $614-651$, VCL-CIT823 $_{815-831}$ in serum of anti-CCP2 ${ }^{+}(n=140)$ versus anti-CCP2 ${ }^{-}$ $(n=38)$ RA patients. Plot depicts the percentage of patient sera positive for one or more citrullinated vinculin peptides. (d) Heat map depicting all patients positive for one or more citrullinated vinculin epitopes $(n=49)$ and their serum reactivity towards different citrullinated epitopes derived from vimentin, fibrinogen and alpha-enolase. Red, positive; green, negative; black, undetermined. Error bars are s.e.m. 
that ACPA are not exclusively directed against citrullinated vinculin as expected (Fig. 1d).

Together these data show that citrullinated vinculin is a selfprotein recognized by RA autoantibodies in a citrullinedependent fashion.

Vinculin is recognized by $T$ cells from HLA-DRB1 ${ }^{\star} 13$ negative donors. We next wished to determine whether the DERAA sequence from vinculin is recognized by human $\mathrm{CD}^{+} \mathrm{T}$ cells. To this end, peripheral blood mononuclear cells (PBMCs) were stimulated with a 15 -mer vinculin-peptide $\left(\mathrm{VCL}_{622-636}\right.$, REEVFDERAANFENH) (VCL-DERAA) for $24 \mathrm{~h}$. We observed a clear reactivity towards this epitope as determined in an interferon- $\gamma$ (IFN- $\gamma$ )-ELISPOT-assay (Supplementary Fig. 1). HLA-DRB1 ${ }^{\star} 13$, especially HLA-DRB $1^{\star} 13: 01$, is strongly associated with protection against $\mathrm{ACPA}^{+} \mathrm{RA}^{17}$. We hypothesize that HLA-DRB1 ${ }^{\star} 13$ protects against $\mathrm{ACPA}^{+}$disease by affecting the generation of DERAA-directed $\mathrm{T}$ cells. Therefore, we stratified donors for HLA-DRB1*13:01 status. We observed a striking difference in IFN- $\gamma$-producing cells depending on HLA-DRB1 ${ }^{\star} 13: 01$-status. The lack of reactivity in HLA-DRB1 ${ }^{\star} 13: 01$-positive donors was not due to a hampered ability of such donors to respond to $\mathrm{T}$ cell antigens as we observed strong response to microbial antigens in both HLA-DRB1*13:01 carriers and non-carriers when stimulated with recall antigens (Fig. 2a). We further confirmed this finding in PBMCs stimulated for 4 days (Supplementary Fig. 2). The differential ability of HLA-DRB1 ${ }^{\star} 13: 01$-positive
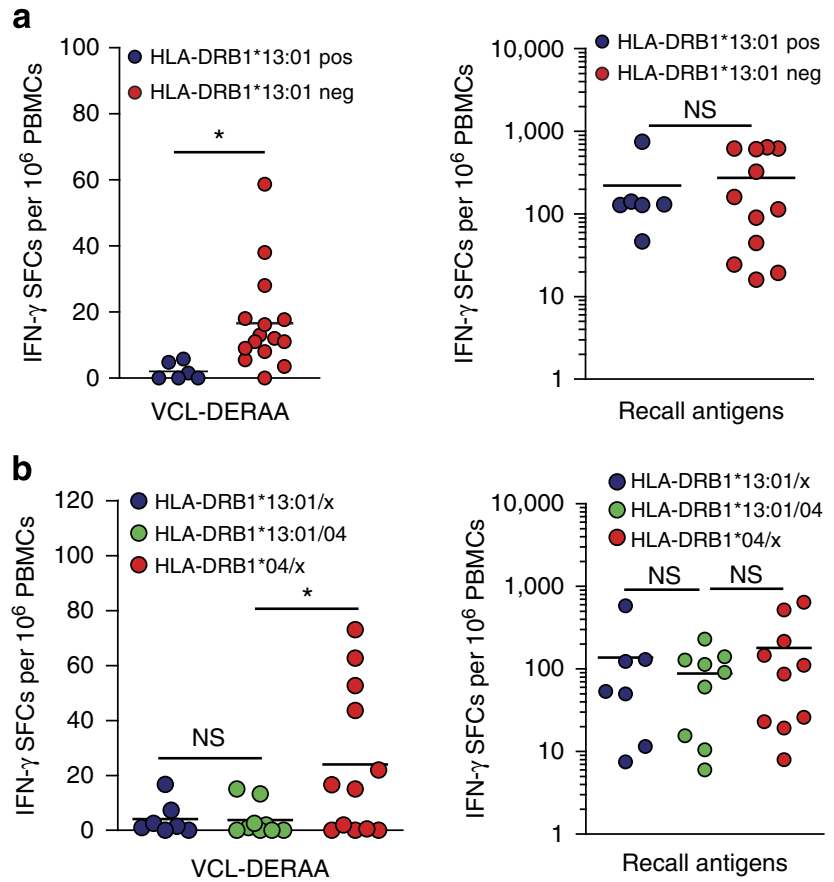

Figure 2 | Citrullinated vinculin is a novel autoantigen targeted by CD4 ${ }^{+} \mathbf{T}$ cells in HLA-DRB1`13-negative donors. (a) IFN- $\gamma$ ELISPOT of PBMCs from healthy individuals stimulated for $24 \mathrm{~h}$ with VCL-DERAA peptide REEVFDERAANFENH $(n=21)$ or with a mix of recall antigens (tetanus, tuberculin, candida, $n=18$ ). Donors were stratified based on HLADRB1*13:01 status. (b) IFN $-\gamma$ ELISPOT of PBMCs of HLA-DRB1*13:01 carriers $(n=7), \mathrm{HLA}^{-\mathrm{DRB} 1}{ }^{\star} 04$ carriers $(n=12)$ and HLA-DRB1*13:01/DRB1*04 donors $(n=9)$, stimulated for $24 \mathrm{~h}$ with VCL-DERAA peptide or with a mix of recall antigens. Each dot represents a unique donor. Two-sided statistical analyses of ELISPOT data were performed using a Mann-Whitney U-test with * indicating $P<0.05$. Neg, negative; NS, not significant; Pos, positive. donors to respond to VCL-DERAA is most likely not due to a general deficiency to present the VCL-DERAA epitope as these donors were heterozygous and thus expressed other HLA molecules that could potentially present VCL-DERAA. Nonetheless, to further confirm that HLA-DRB1*13:01 affects the ability to generate VCL-DERAA-directed T cell responses, we repeated the experiments in a set-up stratified for HLA using PBMCs from HLA-DRB1 ${ }^{\star} 04-$, HLA-DRB1*13:01- and HLA$\mathrm{DRB} 1^{\star} 04{ }^{\star} 13: 01$ heterozygous donors. A significant reduction in IFN- $\gamma$-producing cells was observed in both HLA-DRB1 ${ }^{\star} 13: 01$ carriers and $\mathrm{DRB} 1^{\star} 04 /^{\star} 13: 01$ heterozygous donors as compared with HLA-DRB $1^{\star} 04$ carriers. Again, no difference was observed for recall antigens (Fig. 2b). These data indicate that the lack of detecting VCL-DERAA-directed $\mathrm{T}$ cells is not explained by the inability of HLA-DRB ${ }^{\star} 13$ molecules to present VCL-DERAA, but rather the result of a dominant effect associated with the presence of HLA-DRB1*13.

Thus, vinculin is an autoantigen recognized by circulating VCL-DERAA-directed $\mathrm{CD}^{+} \mathrm{T}$ cells. In HLA-DRB1 ${ }^{\star} 13: 01$ carriers these $\mathrm{T}$ cells are absent. This effect, like the protective effects of HLA-DRB1*13:01 on the development of $\mathrm{ACPA}^{+} \mathrm{RA}$, was present in a dominant fashion, consistent with the notion that HLA-DRB1*13 affects the generation of DERAA-directed $\mathrm{T}$ cells, possibly during thymic selection.

Presentation of Vinculin-DERAA by RA-predisposing HLADQ molecules. HLA-DRB1 alleles predisposing to ACPA ${ }^{+} \mathrm{RA}$ in the Caucasian population are collectively called HLA shared epitope (SE) alleles ${ }^{14,15,29}$. The most common HLA-SE alleles are HLA-DRB ${ }^{\star} 04: 01$ and HLA-DRB $1^{\star} 01: 01$. Using HLA-DRbinding assays, we examined the ability of VCL-DERAA to bind to these HLA molecules, but we could not detect any binding of VCL-DERAA to these alleles (Table 1, Supplementary Fig. 3a,b). The HLA class II region is known for its strong LD. Genes that encode for the HLA-DR-beta chains are inherited in haplotypes with genes that encode for the alpha and beta chain of HLA-DQ. The predisposing HLA-SE alleles are in tight LD with HLA-DQ5 (DQA1*01;DQB1*05:01), HLA-DQ7.3 (DQA1*03:02; DQB1 $\left.{ }^{\star} 03: 01\right)$ and HLA-DQ8 (DQA $\left.{ }^{\star} 03: 01 ; \mathrm{DQB} 1^{\star} 03: 02\right)$ (Fig. 3a,b). In Fig. 3b, the distribution of HLA-DQ molecules in $\mathrm{SE}+$ healthy donors is depicted, showing that these donors are HLA-DQ5-, HLA-DQ7.3- or HLA-DQ8 positive. We therefore

\begin{tabular}{|c|c|c|c|}
\hline Assocation & Subtype & HLA allele & IC50 $(\mu \mathrm{M}$ \\
\hline Susceptibility haplotypes & $\begin{array}{l}\text { HLA-DR } \\
\text { HLA-DQ }\end{array}$ & $\begin{array}{l}\text { DRB1*01:01 }^{\star} \text { DRB1*04:01 } \\
\text { DQ5 } \\
\text { DQ7.3 } \\
\text { DQ8 }\end{array}$ & $\begin{array}{r}>300 \\
>300 \\
39 \\
11 \\
14\end{array}$ \\
\hline $\begin{array}{l}\text { Non-susceptibility } \\
\text { haplotypes }\end{array}$ & $\begin{array}{l}\text { HLA-DR } \\
\text { HLA-DQ }\end{array}$ & $\begin{array}{l}\text { DRB1*13:01 } \\
\text { DRB1*13:02 } \\
\text { DQ6.2 } \\
\text { DQ6.3 } \\
\text { DQ6.4 } \\
\text { DQ7.5 }\end{array}$ & $\begin{array}{l}>300 \\
>300 \\
>300 \\
>300 \\
>300 \\
>300\end{array}$ \\
\hline
\end{tabular}

Affinity of VCL-DERAA for associated HLA class II molecules. Affinity was determined by a competitive binding assay using high-affinity biotinylated peptides. Results are depicted as IC50 value, the concentration of test peptide $(\mu \mathrm{M})$ where $50 \%$ of biotinylated peptide is bound. Experiments were performed at least three times and the average IC50 value between the different experiments is shown. 
a

Susceptibility haplotypes
DRB1

Non-susceptibility haplotypes

13:01

b

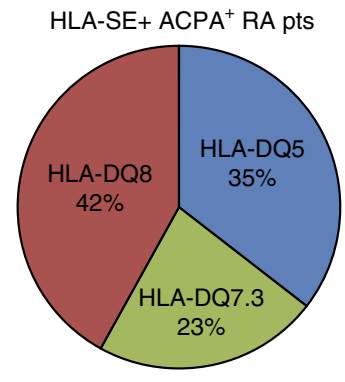

Figure 3 | Presentation to vinculin-DERAA-directed T cells is restricted to RA-predisposing HLA-DQ molecules. (a) Schematic representation of the LD between the HLA-DRB1, HLA-DQA1 and HLA-DQB1 gene in studied haplotypes associated or not associated with susceptibility to ACPA ${ }^{+}$RA. (b) Distribution of HLA-DQ molecules in ACPA ${ }^{+}$RA patients positive for HLA-DR SE alleles $(n=31)$.

next studied the binding of VCL-DERAA to these HLA-DQ alleles and observed binding of the VCL-DERAA peptide to HLA-DQ5, DQ7.3 and DQ8 (Table 1, Supplementary Fig. 3c-e). These data indicate that VCL-DERAA can be presented by HLADQ molecules in LD with predisposing HLA-SE alleles.

To obtain an indication whether the VCL-DERAA can be presented by more HLA molecules, we also studied the ability of additional HLA-DR and HLA-DQ molecules encoded by HLA haplotypes that protect or have no influence on the development of $\mathrm{ACPA}^{+} \mathrm{RA}$. We could not detect binding of VCL-DERAA to these HLA class II alleles (Table 1, Supplementary Fig. 3f-k). Likewise, using an IFN-gamma ELISPOT, VCL-DERAA-directed $\mathrm{T}$ cells were absent in donors negative for predisposing HLA-DQ molecules (Supplementary Fig. 4).

These data indicate that HLA-DQ molecules that predispose to $\mathrm{ACPA}^{+}$disease present the VCL-DERAA peptide, whereas the analysed HLA-DQ and HLA-DR molecules not associated with disease do not present VCL-DERAA.

HLA-DQ-restricted recognition of VCL-DERAA by T cells. To further confirm the presence of VCL-DERAA-directed $\mathrm{T}$ cells and their HLA-restriction, we isolated CD4 ${ }^{+} \mathrm{T}$ cell clone JPT57, which was specific for VCL-DERAA. As shown in Supplementary Fig. 5, this clone proliferated readily and produced large amounts of IFN- $\gamma$ when stimulated with the VCL-DERAA peptide.

When cultured with $\mathrm{B}$ cells from $\mathrm{ACPA}^{+} \mathrm{RA}$ patients pulsed with the VCL-DERAA epitope, the clone not only upregulated CD40L, but also enhanced the production of ACPA in culture, indicating that such $\mathrm{T}$ cells have a phenotype compatible with the ability to provide 'help' to ACPA-producing B cells (Supplementary Fig. 6).

To further confirm that HLA-DQ molecules present the VCL-DERAA peptide, we stimulated the clone with VCLDERAA-pulsed HLA-typed antigen-presenting cells preincubated with HLA class II blocking antibodies (Supplementary Fig. 7). In concordance with the binding studies, anti-HLA-DQ antibodies abrogated $\mathrm{T}$ cell recognition. Interestingly, we observed that JPT57 can recognize VCL-DERAA, presented by both HLA-DQ7.3 and HLA-DQ8 suggesting that this epitope is presented in a similar binding register by these HLA molecules (Supplementary Fig. 8).
Together HLA class II presentation and $\mathrm{T}$ cell recognition of VCL-DERAA was restricted to HLA-DQ molecules that are associated with RA susceptibility.

Identification of microbe-specific $T$ cells targeting DERAA epitopes. We next investigated the presence of the DERAA sequence in microorganisms. A Blast search showed that DERAA is found in $66 \%$ of bacteria and $4 \%$ of viruses (Fig. $4 a$ ). This large number represents a major challenge to identify potential 'crossreactive microorganisms'. To select for relevant microorganisms, we restricted the search to those microorganisms that can cause disease or symptoms in humans and are present in the western world. This approach left us with 219 candidate sequences. We then synthesized eight DERAA-containing peptides from common recall microbes including several bacteria ( $P$. acnes, $S$ enteritidis, B. pertussis, $S$. aureus) and viruses (measles virus, influenza A and human herpesvirus 7). Interestingly, all of these peptides were presented by HLA-DQ7.3 and DQ8 molecules showing that these HLA molecules can efficiently accommodate both the VCL-DERAA epitope as well as microbe-derived DERAA epitopes (Fig. 4b).

To determine whether these microbial-derived epitopes are recognized by human $\mathrm{T}$ cells, we generated $\mathrm{T}$ cell lines by stimulating PBMCs from three healthy HLA-DQ8-positive donors for 7 days with a pool of the eight pathogen-derived peptides (PathMix). Next we determined the presence of PathMix-specific $\mathrm{CD} 4{ }^{+}$IFN- $\gamma$-producing $\mathrm{T}$ cells. As shown in Fig. 4c, such $\mathrm{T}$ cells were readily detectable. Using limiting dilutions, we isolated $\mathrm{T}$ cell clone $\mathrm{D} 2 \mathrm{C} 18$, further confirming the presence of 'microbial-DERAA-directed' T cells (Supplementary Fig. 9). Next we also analysed the presence of 'microbial-DERAAdirected' $\mathrm{T}$ cells by ELISPOT directly ex vivo, allowing the analyses of more donors at higher throughput. Interestingly, PBMCs from HLA-DRB1*13:01 carriers displayed a significantly reduced reaction against these peptides, indicating that the presence of HLA-DRB $1^{\star} 13$ also affects the formation of $\mathrm{T}$ cell responses against DERAA epitopes from microbes (Fig. 4d).

Together these data indicate that HLA-DQ alleles associated with $\mathrm{ACPA}^{+} \mathrm{RA}$ efficiently present both VCL-DERAA and microbe-derived DERAA epitopes and that microbe-specific $\mathrm{T}$ cells directed to DERAA epitopes are readily detected. The presence of $\mathrm{HLA}-\mathrm{DRB} 1^{\star} 13: 01$ affects the formation of these $\mathrm{T}$ cell responses.

Predicting crossreactive microbes by modelling vinculinDERAA presentation. The data presented above demonstrate the presence of microbial- and VCL-DERAA-directed T cells, but do not show if a single $\mathrm{T}$ cell receptor (TCR) can react with both epitopes. To facilitate the search for possible 'crossreactive' DERAA epitopes out of all microbe-derived DERAA sequences, we first determined the binding register of VCL-DERAA using HLA class II-binding assays with amino (N)- and carboxyl (C)terminally truncated and amino-acid-substituted VCL-DERAA peptides as detailed in the Supplementary Note and in Supplementary Figs 10-14. Together these experiments support VFDERAANF (anchors in bold) as the core binding register for both HLA-DQ7.3 and HLA-DQ8. All-atom molecular dynamics (MD) simulations showed that residues Val625 (P1), Glu628 (P4) and Phe633 (P9) make numerous intermolecular polar and nonpolar interactions in the respective pockets. In Fig. 5a-f, we highlight key intermolecular interactions between the VCLDERAA epitope and the HLA-DQ8 molecule. A detailed discussion of the MD results and a quantitative assessment of the intermolecular interactions can be found in the supplementary data (Supplementary Figs 15 and 16, Supplementary Table 1 and 


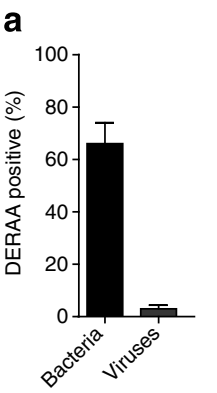

b

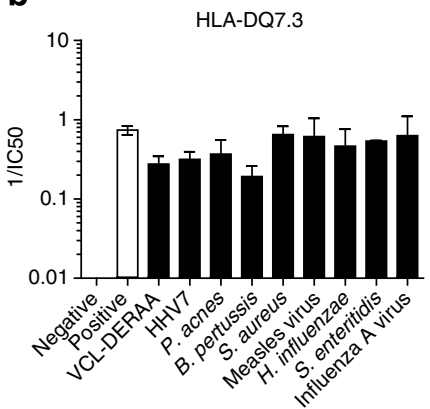

C
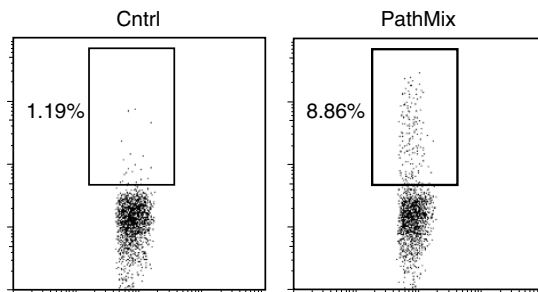

Donor 1

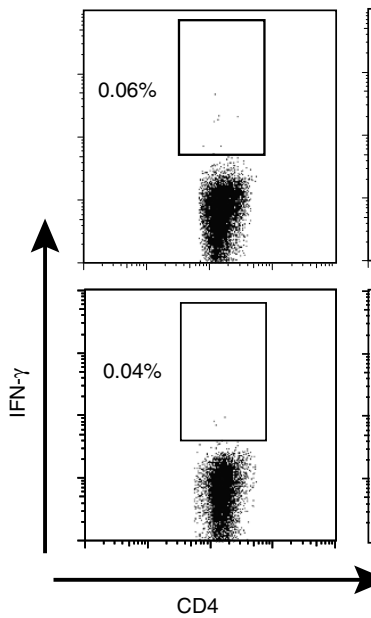

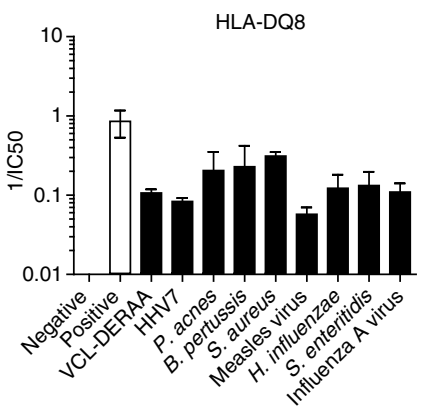

d

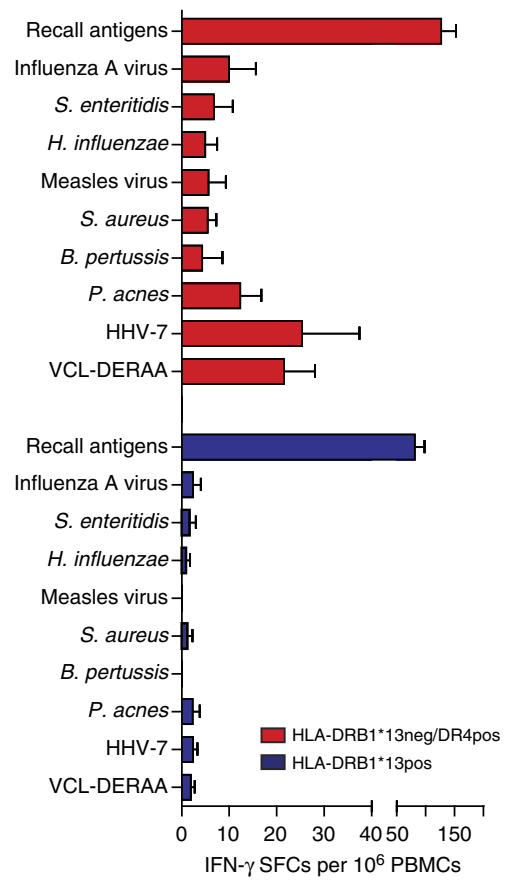

Figure 4 | Identification of pathogen-specific T cells targeting DERAA epitopes in HLA-DRB1^13 negative donors. (a) Frequency of bacteria or viruses positive for a DERAA-containing protein as identified using the NCBI BLAST. List of all bacteria or viruses in blast database was generated and for three random sets of 50 bacteria/viruses a blast search for DERAA was performed. Error bars indicate the s.d. between the three analysed sets. (b) Competitive binding of pathogen-derived DERAA epitopes to HLA-DQ7.3 or HLA-DQ8. Binding experiments were performed at least three times and plots show pooled experiments, the error bars show the variation between the different experiments. (c) Flow cytometry staining of PathMix-directed T cell lines restimulated with PathMix pulsed or unpulsed antigen-presenting cells. Plots are gated on CD14neg/CD4pos/CD25pos T cells. (d) ELISPOT of PBMCs of healthy individuals of HLA-DRB1*13:01 donors $(n=5)$ and HLA-DQ7.3/DQ8 donors $(n=8)$ stimulated for $24 \mathrm{~h}$ with DERAA-containing peptides and recall antigens. Error bars indicate the variation between different donors. Error bars are s.e.m.

Supplementary Note). The MD simulations also indicated that the long protruding side chains of Glu623 (P-2) Glu624 (P-1), Phe626 (P2), Asp627 (P3), Arg629 (P5), Asn632 (P8), Glu634 (P10) and Asn635 (P11) are exposed and could potentially interact with crossreactive TCRs (Fig. $5 \mathrm{~g}$ ). Subsequently we also further confirmed the obtained model using a second type of molecular modelling: energy minimization, which further confirmed possible TCR-contact residues (Supplementary Figs 17 and 18).

To functionally confirm whether a TCR would indeed interact with (some of the) potential TCR-contact residues within the VCL-DERAA peptide, we next determined how the epitope is recognized by the VCL-DERAA-directed T cell clone JPT57. Phe626 (P2) interacts with the JPT57-TCR as its removal results in a large decrease in recognition without affecting HLA-DQ8 binding. (Fig. 5h, Supplementary Fig. 12). C-terminal truncations resulted in a large decrease in $\mathrm{T}$ cell recognition after the removal of Glu634 (P10), showing that this residue is also important for JPT57-TCR interaction (Fig. 5i). Thus, the data obtained using the VCL-DERAA-directed $\mathrm{T}$ cell clone as a functional read-out, are in line with the HLA-binding and molecular modelling studies indicating the sequence VFDERAANFE (anchors in bold) as the minimal epitope required for activation of JPT57. Next we performed alanine substitutions within the minimal epitope to remove critical TCR-interacting residues. Substituting Asn632 (P8) and Phe633 (P9) dramatically impacted T cell recognition, without affecting the binding affinity of VCLDERAA (Fig. 5j,k).

Together these data indicate VFDERAANF (anchors in bold) as the most likely core binding register for HLA-DQ7.3 and HLA-DQ8 and Asn632 and Phe633 as important residues for JPT57-TCR recognition. 
a

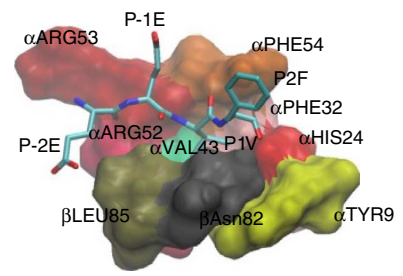

d

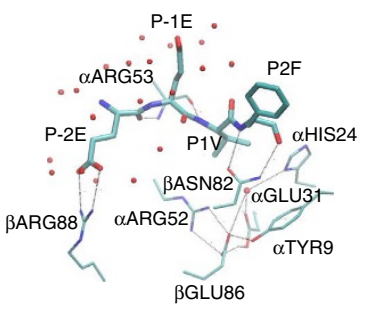

b

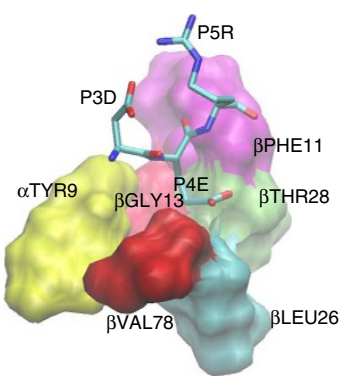

e

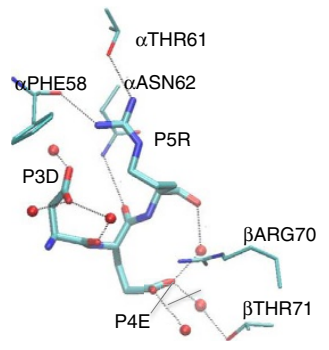

C

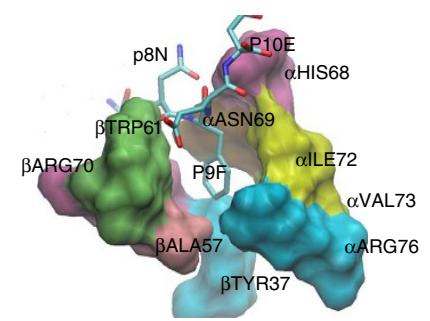

f

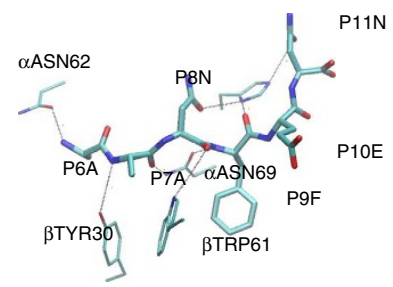

g

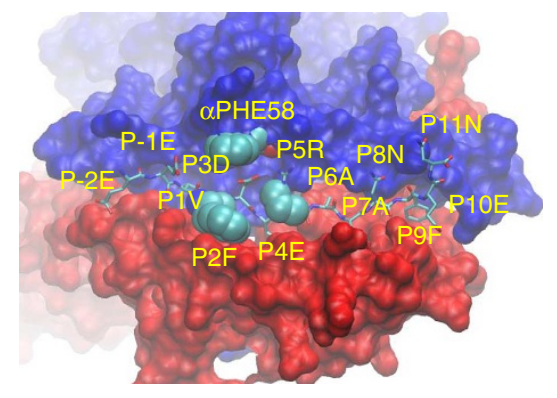

h

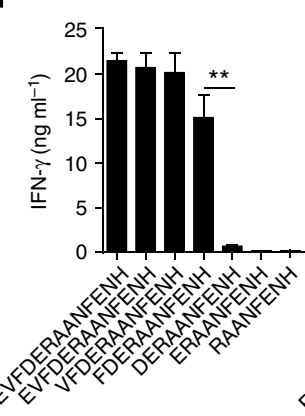

i

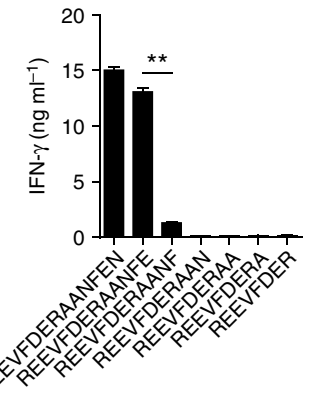

j

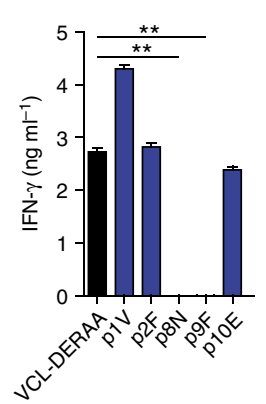

$\mathbf{k}$

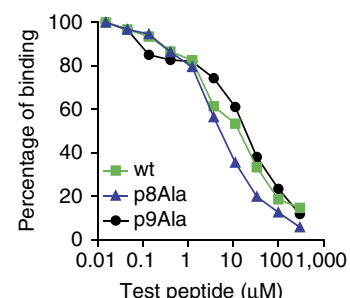

Test peptide $(\mu \mathrm{M})$

Figure 5 | Molecular modelling of HLA:VCL-DERAA complexes identifies critical TCR-contact residues. (a-c) Non-polar contacts between the VCL-DERAA peptide and HLA-DQ8 in pockets P1 (a), P4 (b) and P9 (c). Protein residues are depicted in a surface representation, in distinct colours. (d-f) Hydrogen bonds between the VCL-DERAA peptide and HLA-DQ8 in pockets P1 (d), P4 (e) and P9 (f). Peptide and protein groups are shown, respectively, in thick and thin licorice representation and water molecules as small spheres. Hydrogens are omitted, with the exception of the extra hydrogen in protonated $\alpha$ Glu31. (g) TCR view of the DQ8:VCL-DERAA complex. The peptide main chain is shown in licorice; domains $\alpha$ and $\beta$ are shown in a surface representation, coloured, respectively, in blue and red. Side chains P-2E, P-1E, P2F, P3D, P5R, P8N, P10E and P11N are facing towards the TCR-binding site. The P2F and $\alpha$ Phe58 side chains and the non-polar moiety of P5R form a non-polar cluster, which faces towards the TCR-binding site; the average P2F ring- $\alpha$ Phe58 ring distance is $\sim 8 \AA$. (h-j) IFN- $\gamma$ ELISA on supernatant of T cell clone JPT57 stimulated with unpulsed HLA-DQ8positive antigen-presenting cells and $\mathrm{N}$-truncated (h), C-truncated (i) or alanine-substituted (j) VCL-DERAA peptides. (k) Competitive binding of the VCL-DERAA peptide, and alanine-substituted VCL-DERAA peptides to HLA-DQ8. Binding experiments were performed at least three times and plots show pooled experiments, the error bars show the variation between the different experiments. Experiments involving JPT57 were performed three times and show a representative experiment. Two-sided statistical analysis was performed using a Student's $t$-test with ${ }^{\star \star}$ indicating $P<0.001$. Error bars are s.e.m.

TCR crossreactivity between vinculin and bacterial antigens. Identifying microbes that crossreact with vinculin was challenging due to the large number of potential candidates. Therefore, we used the data presented above to determine if a single TCR can crossreact both to DERAA sequences from microbes and the self-protein vinculin.

As we identified the Asn632 and Phe633 at P8 and P9, respectively, as important for JPT57-TCR interactions, we used 
a

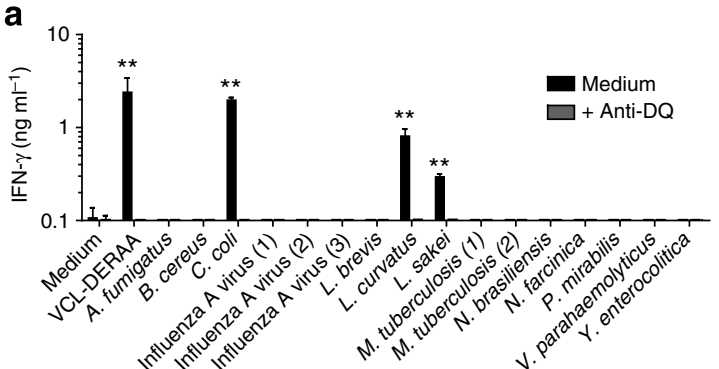

b

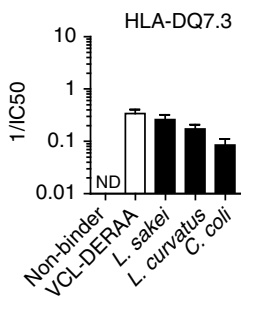

C

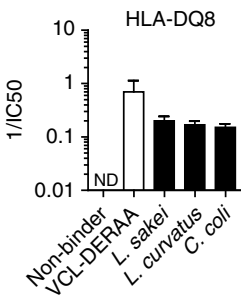

d

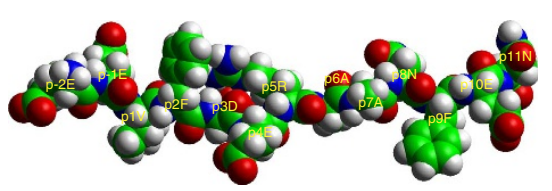

f

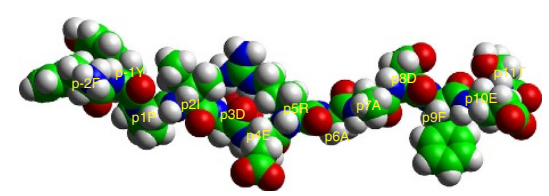

e

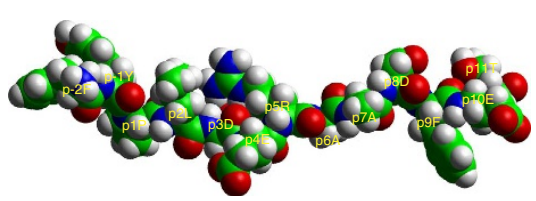

g

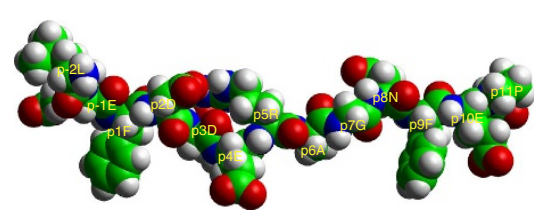

Figure 6 | TCR crossreactivity of vinculin and bacterial DERAA epitopes. (a) IFN- $\gamma$ ELISA on supernatant of T cell clone JPT57 stimulated with HLA-DQ8-positive B-LCLs and alanine-substituted VCL-DERAA peptides. This experiment was performed three times, the plot shows a representative experiment. Two-sided statistical analysis was performed using a Student's $t$-test with * indicating $P<0.05$ and ${ }^{\star \star}$ indicating $P<0.001$. (b,c) Competitive binding of HLA-DQ7.3 (b) and HLA-DQ8 (c) to a non-binding negative control peptide, an unbiotinylated positive control peptide and epitopes from Lactobacillus curvatus, Lactobacillus sakei and Campylobacter coli. Binding experiments were performed three times. The error bars show the variation between the different experiments. (d-g) Side views of HLA-DQ8 complexed with the vinculin-DERAA peptide (d) and peptides derived from Lactobacillus curvatus (e), Lactobacillus sakei (f) and Campylobacter coli $(\mathbf{g})$ in space-filling mode at $\mathrm{pH} 7.4$ (extracellular), obtained by energy minimization as described in the methods section. Each peptide is shown in atomic colour code: oxygen, red; nitrogen, blue; hydrogen, white; carbon, green; sulfur, yellow. Error bars are s.e.m.

the molecular modelling to predict which viral and bacterial epitopes are likely to bind to HLA-DQ8 and harbor P8Asn or P9Phe and are thus likely to crossreact with JPT57. From the 15 peptides identified (Supplementary Table 2), three were able to activate JPT57 in a T cell stimulation assay at concentrations similar to those used for the vinculin peptide. These epitopes were derived from Campylobacter coli, Lactobacillus curvatus and Lactobacillus sakei and crossreacted with JPT57 in an HLA-DQdependent manner (Fig. 6a). Peptide-binding studies revealed that these three peptides bind with an intermediate binding affinity to HLA-DQ7 and HLA-DQ8 (Fig. 6b,c). Molecular models of these bacterial peptides in HLA-DQ8 illustrate the similarities with VCL-DERAA (Fig. 6d-g, Supplementary Figs 19-21).

Thus, these data show that the RA-susceptibility alleles HLADQ7 and HLA-DQ8 can present both VCL-DERAA and related microbe-derived epitopes to $\mathrm{T}$ cells and that such $\mathrm{T}$ cells can be crossreactive to vinculin and bacterial epitopes, thereby providing an explanation for the presence of activated self-reactive $\mathrm{CD} 4^{+} \mathrm{T}$ cells directed to vinculin in peripheral blood.

\section{Discussion}

The strong connection between the HLA locus and RA has been known for more than 35 years. The complex HLA class II associations and the diverse ACPA responses in RA patients suggest the presence of multiple aetiological pathways. To unravel these pathways, identifying the relevant autoantigens is crucial. We here present evidence favouring the involvement of vinculin in the emergence of $\mathrm{ACPA}^{+}$disease. This cytoskeletal protein was recently found to be citrullinated in vivo in the synovial fluid. We now show that it is recognized by ACPA as well, thereby adding it to a still selective list of targets. Moreover, we identified an epitope from vinculin recognized by $\mathrm{CD} 4{ }^{+} \mathrm{T}$ cells restricted to HLA-DQ molecules predisposing to ACPA ${ }^{+}$RA. The core amino-acid sequence (DERAA) is also present in many pathogens and in HLA-DRB1*13, a molecule encoded by an HLA locus associated with protection against $\mathrm{ACPA}^{+} \mathrm{RA}$. We have also shown that a single TCR can recognize both a vinculin-DERAA epitope as well as DERAA epitopes from microbes, indicating the crossreactive nature of 'DERAA'-directed T cell responses. More importantly, such $\mathrm{T}$ cell responses appear absent from donors carrying HLA-DRB1 ${ }^{*} 13$ as DERAA-directed T cell responses to either pathogen- or vinculin-derived DERAA epitopes were lacking in these subjects. Even donors that harboured HLA$\mathrm{DRB1}^{\star} 13$ next to predisposing HLA alleles were unable to respond to vinculin-DERAA.

Together these data indicate a novel pathway that explains several of the protective and predisposing HLA-effects associated with $\mathrm{ACPA}^{+}$RA (Fig. 7). In short, recognition of citrullinated vinculin by $\mathrm{B}$ cells will lead to the presentation of the 'VCLDERAA' epitope in the context of HLA class II molecules. The HLA-DQ molecules genetically linked to the predisposing HLASE-molecules are particularly good in presenting DERAAcontaining peptides. The DERAA-directed T cells primed against various pathogens harbouring DERAA-containing proteins crossreact with the VCL-DERAA peptide and provide help to the $B$ cells, ultimately leading to a strong ACPA response. Subjects born with HLA-DRB1*13, will present the HLA-DRB1*13-derived DERAA-peptide in the thymus, leading to tolerization of the 


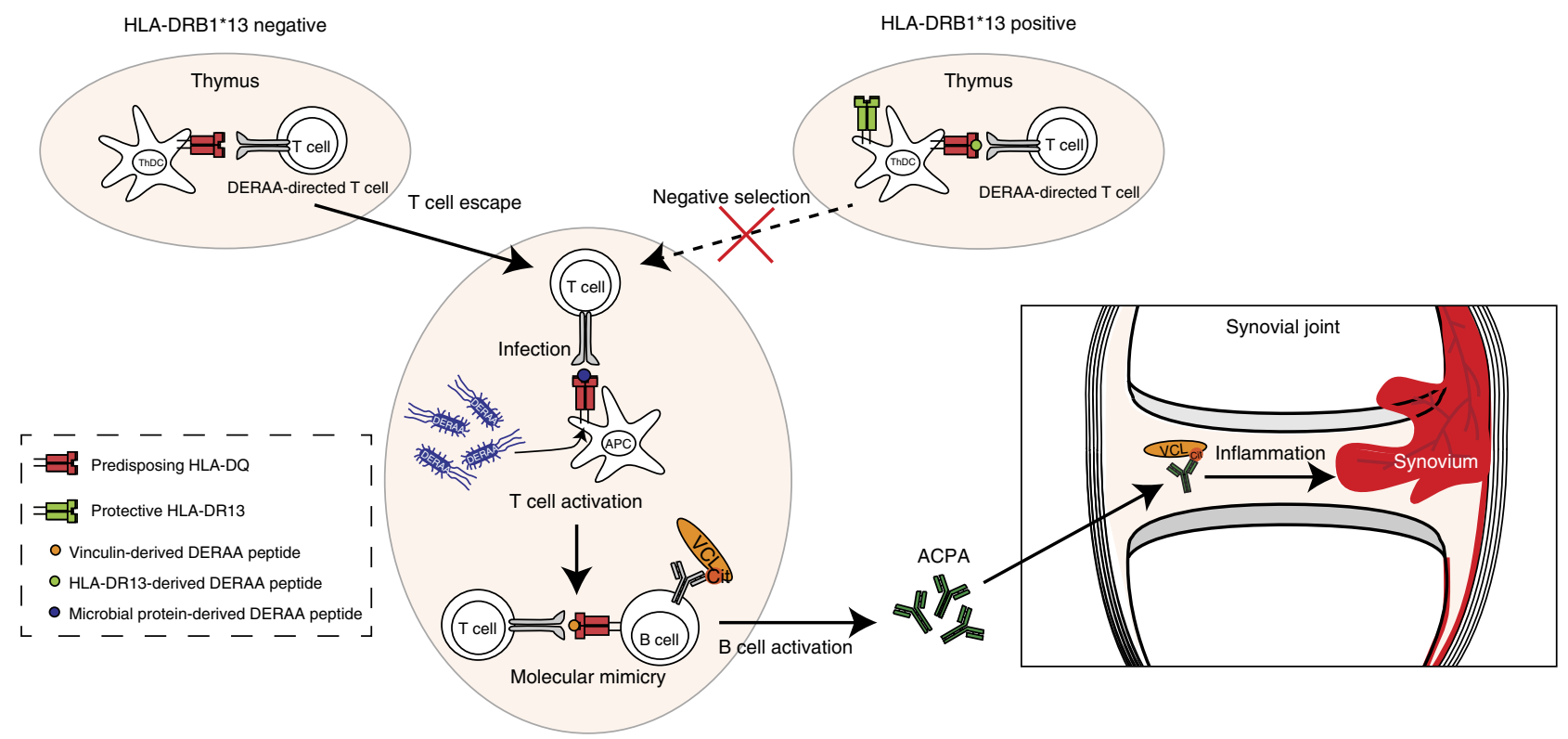

Figure 7 | Schematic representation of the proposed role of DERAA-directed CD4 ${ }^{+} \mathbf{T}$ cells in $\mathbf{A C P A}^{+} \mathbf{R A}$. DERAA-directed T cells are restricted to RA-predisposing HLA-DQ5, -DQ7.3 and -DQ8 molecules. In carriers of these HLA-DQ molecules, DERAA-directed T cells can become activated on contact with microbes. These activated T cells can subsequently crossreact with a DERAA epitope derived from vinculin resulting in the activation of citrullinedirected $B$ cells and the production of ACPA directed to citrullinated vinculin or vinculin-linked proteins. Citrullinated vinculin is present in the synovial compartment and is a target of ACPA. Binding of ACPA to its target can induce antibody-mediated effector mechanisms thereby contributing to synovial inflammation. In HLA-DRB1*13-positive individuals, a HLA-DRB1*13-derived DERAA epitope is presented by predisposing HLA-DQ molecules to CD4 ${ }^{+} \mathrm{T}$ cells resulting in their negative selection, thereby protecting against the development of $A C P A{ }^{+}$RA.

DERAA-reactive $\mathrm{T}$ cell response and hence the inability to provide help to ACPA-producing B cells via this pathway and thereby the emergence of $\mathrm{ACPA}^{+} \mathrm{RA}$ (Fig. 7).

The variation of HLA-DR and HLA-DQ molecules in the human population is enormous. We have shown that predisposing HLA-DQ molecules are particularly good at presenting the VCL-DERAA epitope. Interestingly, the absence of VCL-DERAA affinity for a wide variety of other tested HLA-DR or HLA-DQ molecules could indicate a selective presentation by these HLA risk molecules. Next to a role of predisposing haplotypes, we also focussed on the protective effect of HLA-DRB1 ${ }^{\star} 13$ alleles. However, the DERAA sequence can also be found in other HLA-DRB1 alleles $\left({ }^{\star} 04: 02,{ }^{\star} 11: 02,{ }^{\star} 11: 03\right)$, which are rare in Caucasian populations. These alleles have previously been implicated in protection from $\mathrm{ACPA}^{+} \mathrm{RA}$, but their allele frequency hampers functional studies ${ }^{30-32}$. Interestingly, it has been previously reported that the processing of these alleles results in the generation of a similar HLA-DERAA epitope suggesting that these alleles could all protect via the pathway that we have described ${ }^{22}$.

The place in time at which HLA-DR13 mediates protection from the development of ACPA and/or $\mathrm{ACPA}^{+}$disease, or its relation to epitope spreading of the ACPA response is currently not known and would be relevant to determine in future studies. Recent evidence showed that the ACPA response matures before disease onset and that the HLA system could be involved in this ${ }^{13,33}$. It is intriguing to speculate that infections such as by DERAA-containing microbes are involved in this expansion. Molecular mimicry of self-proteins with pathogenic proteins was proposed as a mechanism to break $\mathrm{T}$ cell tolerance, allowing the development of autoimmune disease ${ }^{26,27}$. Interestingly, the DERAA sequence is also present in proteins from many (common) microbes allowing priming of DERAA-directed T cells. In mouse models, it was shown that low-avidity $\mathrm{T}$ cells to tissue-restricted antigens can persist without signs of anergy and unresponsiveness. Infection lowers the threshold for $\mathrm{T}$ cell activation resulting in the induction of autoimmunity and memory formation ${ }^{3}$. Infection could also induce autoimmunity via molecular mimicry of microbial proteins with self-proteins. We now identified crossreactive epitopes from the gut-residing bacteria L. sakei, L. curvatus and C. coli. It was shown that acute gastrointestinal infections can induce loss of $\mathrm{T}$ cell tolerance to (commensal) gut microbes, resulting in the activation of microbiota-specific $\mathrm{T}$ cells, their differentiation to inflammatory effector cells and formation of memory $\mathrm{T}$ cells ${ }^{35}$. A recent study on the fecal microbiota of RA patients compared with controls demonstrated a significant increase in Lactobacillus species, together providing a rationale for a role of such bacterial species in the formation of DERAA-directed $\mathrm{T}$ cell responses ${ }^{36}$.

Together our study provides a mechanistic clue on the HLARA connection, including both predisposing and protective HLA effect, and warrants further studies addressing the possibility to target DERAA-directed $\mathrm{T}$ cells in the prevention of ACPA ${ }^{+} \mathrm{RA}$.

\section{Methods}

Cells and sera. HLA-typed buffy coats from healthy volunteers were obtained from the blood bank (Sanquin, The Netherlands). PBMCs and sera from RA patients were derived from patients participating in the Leiden Early Arthritis Clinic cohort ${ }^{37}$. All RA patients fulfilled the American College of Rheumatology (formerly the American Rheumatism Association) 1987 revised criteria for the classification of RA. A total of 178 RA patients were used in the current analyses. Patient samples were compared with 80 control samples from healthy individuals also living in the Leiden area. PBMCs were isolated using a standard Ficoll procedure. The protocols were approved by the Leiden University Medical Center ethics committee and informed consent was obtained.

Peptides. Peptides were synthesized according to standard Fmoc (N-(9-fluorenyl)methoxycarbonyl) chemistry using a SyroII peptide synthesizer (MultiSynTech, Witten, Germany). The integrity of the peptides was checked using reverse-phase high-performance liquid chromatography and mass spectrometry. For vinculin ELISPOT experiments, HLA class II-binding studies and T cell activation studies 15 -mer vinculin epitope VCL $_{622-636}$ (VCL-DERAA; 
REEVFDERAANFENH) was used. To determine the peptide-binding register, the VCL622-636 peptide was modified: Truncated on the N- or C terminus or alanine-/arginine-substituted at different positions. For ELISPOT assays against common pathogens, pathogenic peptides were used derived from measles virus (SSRASDERAAHLPTS), influenza A virus (VFEFSDERAANPIVP), human herpesvirus 7 (LAARADERAAFPDVG), Bordetella pertussis (SPNLTDERAAQAGVT), Staphylococcus aureus (QDMNDDERAALTMAM), Haemophilus influenzae (RFHGDDERAAKVYEN), Salmonella enteritidis (PLMMDDERAAKVYEN) and Propionibacterium acnes (EEVFTDERAARLSHV). For the generation of $\mathrm{T}$ cell lines, these eight pathogenic peptides were pooled.

Cell lines. The following Epstein-Barr virus-transformed lymphoblastoid B-cell lines were used: $\mathrm{BSM}\left(\mathrm{DRB1}{ }^{\star} 04: 01 ; \mathrm{DQA1}{ }^{\star} 03: 01 ; \mathrm{DQB1}^{\star}{ }^{\star} 03: 02\right.$, IHW9032), BOLETH (DRB1 ${ }^{\star} 04: 01$; DQA1 ${ }^{\star} 03: 01$; DQB1 ${ }^{*} 03: 02$, IHW9031), BM21 (DQA1*05: 01;DQB1*03:01, IHW9043), JSM (DQA1 ${ }^{*} 03: 02 ; \mathrm{DQB1}^{*} 03: 01$ ), APD (DRB1 ${ }^{*} 13: 01$; DQA1 ${ }^{*} 01: 03 ; \mathrm{DQB1} 1^{\star} 06: 03$, IHW9291), BC34 (DRB1*13:02;DQA1*01:02;DQB1 $\left.{ }^{*} 06: 04\right)$, WT8 (DQA1*01:02;DQB1*06:02, IHW9017), KAS116 (DRB1*01:01; $\mathrm{DQA1}^{*} 01: 02$; $\mathrm{DQB1}{ }^{*} 05: 01$, IHW9003) and 721.82 (DR/DQ-negative) ${ }^{38}$. Cells were maintained in IMDM (Lonza) supplemented with 10\% heat-inactivated fetal calf serum. JSM and BC34 cells are derived from healthy HLA-typed donors that were Epstein-Barr virus transformed.

HLA class II competitive peptide-binding assay. Peptide-binding assays were performed, as described previously ${ }^{39}$. In short, cell lysates from HLA class II homozygous B-lymphoblastoid cell lines were incubated on SPVL3- (anti-HLADQ) or B8.11.2- (anti-HLA-DR) coated $\left(10 \mu \mathrm{g} \mathrm{ml}^{-1}\right)$ FluoroNunc 96 -well plates at $4^{\circ} \mathrm{C}$ overnight. Titration ranges of the tested peptides $(0$ to $300 \mu \mathrm{M})$ were mixed with a fixed concentration $(0.6 \mu \mathrm{M})$ of biotinylated indicator peptide and added to the wells. Bound indicator peptide was detected using europium-streptavidin (Perkin Elmer, Boston, MA) and measured in a time-resolved fluorometer (PerkinElmer, Wallac Victor2). IC50 values were calculated based on the observed binding of the test peptide against the fixed concentration indicator peptide. The IC50 value depicts the concentration of test peptide required for a loss of $50 \%$ of the indicator peptide signal.

Enzyme-linked immunosorbent spot assay. PBMCs were incubated in 96-well Multiscreen HA plates (Millipore) precoated with $5 \mu \mathrm{g} \mathrm{ml}^{-1}$ anti-IFN- $\gamma$ capture antibody (clone 1-D1K; Mabtech) at $5 \times 10^{5}$ cells per well and stimulated in $\mathrm{X}$-VIVO medium (LONZA) with $5 \mu \mathrm{g} \mathrm{ml}^{-1}$ peptide or with a mix of recall antigens consisting of $0.75 \mathrm{Lf} \mathrm{ml}^{-1}$ tetanus toxoid (Netherlands Vaccine Institute), $0.5 \mu \mathrm{g} \mathrm{ml}^{-1}$ tuberculin purified protein derivative (Netherlands Vaccine Institute) and $0.005 \%$ Candida albicans (HAL allergy). After $24 \mathrm{~h}$ incubation at $37^{\circ} \mathrm{C}$, plates were extensively washed and incubated with $0.3 \mu \mathrm{g} \mathrm{ml}{ }^{-1}$ biotin-labelled anti-IFN$\gamma$ detection antibody (clone 7-B6-1; Mabtech) for $2 \mathrm{~h}$ at RT, with $1,000 \times$ diluted ExtrAvidin-Alkaline phosphatase (Sigma-Aldrich) for $1 \mathrm{~h}$ at RT and with 5-Bromo-4-chloro-3-indolyl phosphate/Nitro blue tetrazolium (Sigma-Aldrich). Spots were analysed using the BioSys Bioreader 3000pro. Circular spots with a size of $80-450 \mu \mathrm{m}$ were included.

Flow cytometry. Polyclonal $\mathrm{CD} 4^{+} \mathrm{T}$ cell lines were generated by stimulating $3 \times 10^{6} \mathrm{PBMCs}$ per well in a 24 -well plate with $5 \mu \mathrm{g} \mathrm{ml}{ }^{-1}$ peptide for 7 days in IMDM supplemented with $5 \%$ human serum (Sanquin). After 7 days, $1.5 \times 10^{6}$ autologous PBMCs per well were plated in 24-well plates for $2 \mathrm{~h}$. After $2 \mathrm{~h}$, nonadherent cells were removed and adherent cells were pulsed with $5 \mu \mathrm{g} \mathrm{ml}^{-1}$ peptide and used as feeders for $10^{6} \mathrm{~T}$ cells. After $1 \mathrm{~h}, 10 \mu \mathrm{g} \mathrm{ml}^{-1}$ brefeldin A was added. Cells were incubated overnight and used for intracellular cytokine staining. The cells were incubated with fluorochrome-conjugated antibodies recognizing CD4, (Clone RPA-T4; BD biosciences), CD14 (Clone 61D3; eBioscience) and CD25 (Clone M-A251; BD biosciences), after which they were permeabilized using CytoFix CytoPerm Kit (BD Biosciences). After washing, cells were incubated with PE-labelled anti-IFN- $\gamma$ or matching isotype control. Cells were taken up in $1 \%$ paraformaldehyde until flow cytometric acquisition. Flow cytometry was performed on FACS Calibur (BD biosciences) or LSR II (BD biosciences). Analysis was performed using FACS Diva (BD biosciences) and FlowJo software.

T cell cloning. JPT57 was generated from an HLA-DRB1*04:05/01:01;DQ8/DQ5 donor. PBMCs were cultured for 7 days in the presence of $10 \mu \mathrm{g} \mathrm{ml}^{-1}$ of VCLDERAA peptide and restimulated with VCL-DERAA-pulsed antigen-presenting cells. After 1 week, cells were restimulated with $150 \mathrm{U} \mathrm{ml}^{-1}$ rIL-2. After two rounds of restimulation, $\mathrm{T}$ cell lines were tested for their specificity. The wells responding to VCL-DERAA peptide were cloned in a limiting dilution of 0.3 cells per well resulting in the isolation of clone JPT57.

$\mathrm{T}$ cell clone $\mathrm{D} 2 \mathrm{C} 18$ was generated from an HLA-DRB1 ${ }^{*} 04: 01$;DQ2/DQ8 positive donor. $\mathrm{CD} 4{ }^{+} \mathrm{T}$ cells and $\mathrm{CD} 14^{+}$monocytes were isolated from PBMCs using antibodies bound to magnetic beads from, respectively, Dynal and Miltenyi. $\mathrm{CD} 4{ }^{+} \mathrm{T}$ cells were labelled with $1 \mu \mathrm{M}$ CFSE (Invitrogen) and incubated in a 2:1 ratio with $\mathrm{CD} 14^{+}$monocytes with $30 \mu \mathrm{g} \mathrm{ml}{ }^{-1}$ PathMix. After 6 days, $\mathrm{CD} 3_{\text {pos }} \mathrm{CD} 4_{\text {pos }} \mathrm{CD} 25_{\text {pos }} \mathrm{CD} 14_{\text {neg }} \mathrm{DAPI}_{\text {neg }} \mathrm{CFSE}_{\text {low }}$ cells were sorted by FACS aria
(BD). Isolated CD4 ${ }^{+} \mathrm{T}$ cells were rested in medium containing $20 \mathrm{IU} \mathrm{ml}^{-1} \mathrm{rIL}-2$ (Peprotech). After 3 days, the cells were cloned in a limiting dilution of 0.3 cells per well resulting in the isolation of $\mathrm{CD} 4^{+} \mathrm{T}$ cell clone $\mathrm{D} 2 \mathrm{C} 18$.

T cell activation. To determine IFN- $\gamma$ production by $\mathrm{T}$ cell clones in response to peptide stimulation, 50,000 $\mathrm{T}$ cells were incubated in a 1:1 ratio with B-LCL lines pulsed with $10 \mu \mathrm{g} \mathrm{ml}^{-1}$ of peptide for 3-6h. After 3 days, the supernatant was collected and an IFN- $\gamma$ ELISA (eBioscience) was used to determine the concentration of IFN- $\gamma$. For measurement of T cell proliferation, 50,000 T cells were incubated in a 1:1 ratio with radiated (3000RAD) autologous PBMCs pulsed with $10 \mathrm{~g} \mathrm{ml}^{-1}$ of peptide for $3-6 \mathrm{~h}$ in IMDM supplemented with $5 \%$ human serum. After 3 days, cells were cultured for $16-20 \mathrm{~h}$ with $\left[{ }^{3} \mathrm{H}\right]$ thymidine $(0.5 \mu \mathrm{Ci}$ per well) ${ }^{3} \mathrm{H}$ incorporation was measured by liquid scintillation counting (1450 MicroBeta TriLux; PerkinElmer). Blocking experiments were performed by preincubating antigen-presenting cells for $1 \mathrm{~h}$ with $20 \mu \mathrm{g} \mathrm{ml}^{-1}$ anti-DQ (SPVL3), anti-DR (B8.11.2) and anti-DP (B7.21) blocking antibodies.

Detection of anti-citrullinated vinculin antibodies. Citrullinated vinculin was generated by incubation of $50 \mu \mathrm{g}$ vinculin protein (Sanbio) in a volume of $200 \mu \mathrm{l}$ containing $0.1 \mathrm{M}$ Tris- $\mathrm{HCl} \mathrm{pH} \mathrm{7.6,} 0.15 \mathrm{M} \mathrm{CaCl}_{2}$, and $10 \mathrm{U}$ PAD4 (Sigma) for $4 \mathrm{~h}$ at $37^{\circ} \mathrm{C}$. Unmodified vinculin protein was generated by incubation of vinculin with PAD4 without $\mathrm{CaCl}_{2}$. Citrullinated and unmodified vinculin were loaded onto $10 \%$ SDS-polyacrylamide gels and transferred onto blotting membranes. Blots were blocked, washed and incubated in 1:500 diluted serum overnight at $4{ }^{\circ} \mathrm{C}$. The sera were either $\mathrm{ACPA}^{+}$or $\mathrm{ACPA}^{-}$as determined by ELISA. Blots were incubated with horseradish peroxidase-labelled rabbit anti-human IgG (Dako) and visualized with chemiluminescence (ECL, Amersham). To analyse reactivity to vinculin by a monoclonal ACPA (anti-cFIB1.1, citrullinated fibrinogen), vinculin- or citrullinated vinculin-coated Nunc plates were incubated with $0.2 \mu \mathrm{g} \mathrm{ml}^{-1}$ anti-cFIB1.1 for $2 \mathrm{~h}$ at room temperature ${ }^{28}$. Bound antibody was detected using horseradish peroxidase-labelled rabbit anti-human IgG (Dako) and visualized with ABTS. Peptide ELISA was performed as described previously using biotinylated peptides coated on streptavidin-precoated plates ${ }^{40}$.

B-cell activation by JPT57 cells. B cells were isolated from PBMCs of HLA-DQ8positive healthy donors or ACPA-positive RA patients by magnetic anti-CD19beads (Invitrogen). B cells were cultured in IMDM supplemented with $10 \%$ fetal calf serum, penicillin, streptomycin and glutamax. From healthy subjects, 30,000 B cells were co-cultured with different number of JPT57 cells in the presence of $5 \mu \mathrm{g} \mathrm{ml}^{-1}$ anti-IgM (JacksonImmunoresearch Laboratories) and with $10 \mu \mathrm{g} \mathrm{ml}^{-1}$ VCL-DERAA or $1 \mu \mathrm{g} \mathrm{ml}^{-1}$ PHA in round-bottom 96-well plates. After 7 days, IgG production by $\mathrm{B}$ cells was determined using a total IgG ELISA (Bethyl laboratories). From RA patients, 20,000 B cells were pulsed with $10 \mu \mathrm{g} \mathrm{ml}^{-1}$ VCL-DERAA peptide and co-cultured with 20,000 JPT57 cells in the presence of $5 \mu \mathrm{g} \mathrm{ml}{ }^{-1}$ antiIgM in round-bottom 96-well plates. After 7 days, ACPA production was determined by ELISA measuring reactivity against the CCP2-peptide in individual wells (EuroDiagnostica).

Energy minimization. Molecular simulations of HLA-DQ8 $\left(\mathrm{Al}^{\star} 0301 / \mathrm{B} 1^{\star} 302\right)$ and HLA-DQ7.3 $\left(\mathrm{Al}^{*} 0302 / \mathrm{Bl}^{*} 0301\right)$ complexed with various peptides, experimentally shown to bind to these molecules, were carried out as previously described using the Discover Suite (programmes InsightII and Discover) of Accelrys (San Diego, CA, release of 2005) on a Silicon Graphics Fuel instrument, using a minimization approach previously described ${ }^{41}$, that is, 1,000 steps of the steepest gradient method, followed by 1,000 steps of the conjugate gradient method. Records of the energy of every step showed a continuous decrease in energy without any local minima and an energy asymptote for the last 300-400 steps of the conjugate gradient method. The base molecule was the crystal structure of HLA-DQ8 $\left(\mathrm{A} 1^{*} 0301 / \mathrm{B} 1^{*} 0302\right)$ with bound the insulin B11-23 peptide ${ }^{42}$. The region HLADQ $\beta 105-112$ for which full coordinates were not available in the original data, was constructed by molecular replacement of the respective region from HLA-DR1 $\left({ }^{43}\right)$ after superposition of the $\beta$-plated sheet regions of the two molecules in the $\alpha 1 \beta 1$ domains. The binding registers of the vinculin and the bound microbial peptides were decided from the binding of truncated peptides as well as Arg-substituted peptides in presumed anchor positions; energy minimization of successive registers confirmed the registers predicted from the binding data. The rotamers for the peptide residues were chosen from a library of rotamers provided by the software database, to have no molecular clashes with the residues of HLA-DQ8. Minimizations were carried out either at $\mathrm{pH} 5.4$ (endosomal pH) or 7.4 (extracellular). There are no similarly charged residues (for example, Glu-Glu) with their charged groups so close to each other as to require that one of the residues be uncharged. Occasionally runs were performed on a Silicon Graphics Octane instrument with previous releases of the same software with very similar results. Figures are drawn using the WebLabViewer v.3.5 and DSViewerPro software of Accelrys, the latter currently freely available on the web. In the figures a side view of the bound peptide with the eye level placed at the level of the peptide backbone and parallel to the HLA-DQ $\beta$-sheet floor is visualized with an atomic colour code as in the respective figure legend. In the Supplementary Figures, the $\alpha 1 \beta 1$ domains of the modelled HLA-DQ molecules in complex with given bound 
peptides are depicted in van der Waals surface representation, with colour and depiction conventions identical to those for the other figures. Several visible residues from the HLA-DQ molecule in contact with the antigenic peptide and potential contact with a cognate TCR in canonical orientation are shown in stick form with a transparent surface (atomic colour code: oxygen, red; nitrogen, blue; hydrogen, white; carbon, orange; sulfur, yellow). The antigenic peptide in the groove is shown in space filling form with the same atomic colour code as in Fig. $6 \mathrm{~d}-\mathrm{g}$. Coordinates of all complexes shown in the various figures have been deposited in the Figshare repository under accession codes 1294716

MD simulations. The simulated system consisted of the entire DQ8 molecule and the 13-residue peptide with the vinculin sequence Glu-Glu-Val-Phe-Asp-Glu-ArgAla-Ala-Asn-Phe-Glu-Asn. Titratable residues were assigned their most common ionization state at physiological $\mathrm{pH}$, with the exception of DQ8 residue $\alpha \mathrm{Glu} 31$, which was protonated. In the crystallographic structure of the DQ8:insulin complex, residues $\alpha$ Glu31 and $\beta$ Glu86 are in direct contact ${ }^{42}$ and their geometry and interactions with nearby residues and a crystallographic water suggest that at least one of them is protonated. A similar conclusion was reached for a pair of Glu and Asp residues in the pocket P6 of DR and I-E molecules ${ }^{44}$. We used the empirical model Propka ${ }^{45}$ and a constant-pH Monte Carlo approach implemented in the program PROTEUS ${ }^{46}$ to compute the $\mathrm{pK}$ of titratable groups in the crystallographic structure of HLA-DQ8, both in the absence and the presence of the peptides insulin and VCL-DERAA. Both methods agreed that the residues $\alpha \mathrm{GLU} 31$ and $\beta$ GLU86, near pocket P1, are strongly correlated; the predicted $\mathrm{pKa}$ values suggested that one of them should be protonated, most probably $\alpha \mathrm{Glu} 31$.

The initial coordinates of the protein heavy atoms were taken from the crystallographic structure of the DQ8:insulin complex (PDB accession code $1 \mathrm{KK} 8)^{42}$. The peptide main chain heavy atoms were placed at the corresponding coordinates of the insulin main chain. Hydrogens were positioned by the HBUILD algorithm of the CHARMM programme ${ }^{47}$. The peptide side chain initial conformations were optimized with the program PROTEUS ${ }^{45}$. An additional control simulation studied the DQ8:insulin complex; for this system, the initial coordinates of the protein and peptide were taken from the corresponding crystallographic structure (PDB accession code $1 \mathrm{JK} 8)^{42}$.

The initial set-up of the simulation system was performed with the CHARMMGUI interface ${ }^{48}$. A total of 70 crystallographic waters of the DQ8:insulin complex were retained. For the vinculin complex, crystallographic waters were minimized for 100 steps before the simulation, with the protein and peptide atoms kept fixed. The ligand complexes were immersed in a periodically replicated water box with the shape of a $117-\AA$ truncated octahedron. Overlapping water molecules were omitted and 17 potassium anions were added (14 ions in the insulin complex), to neutralize the total charge. The final complex had 120,324 atoms (6,166 proteinligand atoms); the insulin complex had 120,504 atoms (6,172 protein-ligand atoms).

The simulations employed the molecular mechanics program CHARMM c37b2 (ref. 47). Protein atomic parameters were taken from the CHARMM36 all-atom force field with a CMAP backbone phi/psi energy correction ${ }^{49,50}$. Water parameters corresponded to the modified TIP3P water model ${ }^{51,52}$. Electrostatic interactions were calculated without truncation by the particle-mesh Ewald method $^{53}$, with a parameter $\kappa=0.34$ for the charge screening, and sixth-order splines for the mesh interpolations. The Lennard-Jones interactions between atom pairs were switched to zero at a cutoff distance of $12 \AA$. The temperature was kept at $T=300 \mathrm{~K}$ by a Nose-Hoover thermostat ${ }^{54}$ with a mass of $2,000 \mathrm{kcal} \mathrm{mol}^{-1} \mathrm{ps}^{-2}$ for the thermostat. The pressure was maintained at $P=1$ atm with a Langevin piston $^{55,56}$. The piston mass was set to $1 / 20$ of the total mass of the system and the collision frequency was set to $20 \mathrm{ps}^{-1}$. The classical equations of motion were solved by the leap-frog integrator. Bond lengths to hydrogen atoms and the internal water geometry were constrained to standard values via the SHAKE algorithm ${ }^{57}$, implemented into CHARMM.

The structure was initially optimized by 100 energy minimization steps with the steepest-descent and adopted-basis Newton-Raphson algorithms. This was followed by an equilibration run, consisting of three 200-ps segments, in which the harmonic force constants were gradually lowered from 10 to $0 \mathrm{kcal} \mathrm{mol}^{-1} \AA^{-2}$. The production simulation had a duration of $3 \mathrm{~ns}$ (vinculin complex) and $4 \mathrm{~ns}$ (vinculin complex with ionized $\alpha$ Glu31 and insulin complex). A total of 300 and 400 snapshots were analysed for the vinculin- and insulin-DQ8 complex, respectively, extracted every $10 \mathrm{ps}$. All simulations were conducted with version c37b2 of the CHARMM programme ${ }^{47}$. Hydrogen bond occupancies and averaged intermolecular interaction energies were computed by in-house scripts. Molecular visualization was performed using the program $\mathrm{VMD}^{58}$

The interaction energies of selected peptide-protein residue pairs were computed by the following equation ${ }^{59,60}$ :

$$
\Delta G_{R R^{\prime}}^{\text {inte }}=\underbrace{\sum_{i \in R} \sum_{j \in R^{\prime}}\left(E_{i j}^{\text {Coul }}+E_{i j}^{\mathrm{GB}}\right)}_{\Delta G_{R R^{\prime}}^{\text {polar }}}+\underbrace{\sum_{i \in R} \sum_{j \in R^{\prime}} E_{i j}^{\mathrm{vW}}+\sigma \sum_{i \in R, R^{\prime}} \Delta S_{i}}_{\Delta G_{R R^{\prime}}^{\text {nopolar }}}
$$

The first and second group of terms on the right-hand side of equation (1) describe, respectively, polar and non-polar interactions between R and R'; 'Coul' denotes Coulombic interaction, 'GB' denotes generalized born interaction, $\Delta S_{\mathrm{i}}$ is the change in the solvent accessible surface area of atom on binding and $\sigma$ is a surface tension coefficient. The residue-pair interaction energies of equation (1) include solventmediated effects via the above GB and surface area terms. In the calculations of Supplementary Fig. 15, R and $\mathrm{R}^{\prime}$ are distinct ligand and protein residues.

We employed the GBSW Generalized Born model ${ }^{61,62}$, as implemented in the CHARMM programme. The coefficient $\sigma$ was set to $0.005 \mathrm{kcal} \mathrm{mol}^{-1} \AA^{2}$, for consistency with the GBSW parameterization. To compute the GB contributions, we removed all waters and ions from the simulation system and set the charge to zero for protein and peptide atoms other than those belonging to residues $\mathrm{R}$ and $\mathrm{R}^{\prime}$, respectively. The last term contains the difference in solvent accessible surface areas of groups $\mathrm{R}$ and $\mathrm{R}^{\prime}$ in the complex and unbound states. Coordinates of all complexes shown in the various figures have been deposited in the Figshare repository under accession code 1294716.

\section{References}

1. Schellekens, G. A., de Jong, B. A., van den Hoogen, F. H., van de Putte, L. B. \& van Venrooij, W. J. Citrulline is an essential constituent of antigenic determinants recognized by rheumatoid arthritis-specific autoantibodies. J. Clin. Invest. 101, 273-281 (1998).

2. Girbal-Neuhauser, E. et al. The epitopes targeted by the rheumatoid arthritisassociated antifilaggrin autoantibodies are posttranslationally generated on various sites of (pro)filaggrin by deimination of arginine residues. J. Immunol. 162, 585-594 (1999).

3. Anzilotti, C., Pratesi, F., Tommasi, C. \& Migliorini, P. Peptidylarginine deiminase 4 and citrullination in health and disease. Autoimmun. Rev. 9, 158-160 (2010).

4. van Beers, J. J. et al. The rheumatoid arthritis synovial fluid citrullinome reveals novel citrullinated epitopes in apolipoprotein E, myeloid nuclear differentiation antigen, and beta-actin. Arthritis Rheum. 65, 69-80 (2013).

5. Vossenaar, E. R. et al. The presence of citrullinated proteins is not specific for rheumatoid synovial tissue. Arthritis Rheum. 50, 3485-3494 (2004).

6. Ioan-Facsinay, A. et al. Anti-cyclic citrullinated peptide antibodies are a collection of anti-citrullinated protein antibodies and contain overlapping and non-overlapping reactivities. Ann. Rheum. Dis. 70, 188-193 (2011).

7. Amara, K. et al. Monoclonal IgG antibodies generated from joint-derived B cells of RA patients have a strong bias toward citrullinated autoantigen recognition. J. Exp. Med. 210, 445-455 (2013).

8. Snir, O. et al. Antibodies to several citrullinated antigens are enriched in the joints of rheumatoid arthritis patients. Arthritis Rheum. 62, 44-52 (2010).

9. van Gaalen, F. A. et al. Autoantibodies to cyclic citrullinated peptides predict progression to rheumatoid arthritis in patients with undifferentiated arthritis: a prospective cohort study. Arthritis Rheum. 50, 709-715 (2004).

10. Rantapaa-Dahlqvist, S. et al. Antibodies against cyclic citrullinated peptide and IgA rheumatoid factor predict the development of rheumatoid arthritis. Arthritis Rheum. 48, 2741-2749 (2003).

11. Huizinga, T. W. et al. Refining the complex rheumatoid arthritis phenotype based on specificity of the HLA-DRB1 shared epitope for antibodies to citrullinated proteins. Arthritis Rheum. 52, 3433-3438 (2005)

12. Verpoort, K. N. et al. Association of HLA-DR3 with anti-cyclic citrullinated peptide antibody-negative rheumatoid arthritis. Arthritis Rheum. 52, 3058-3062 (2005).

13. Willemze, A., Trouw, L. A., Toes, R. E. \& Huizinga, T. W. The influence of ACPA status and characteristics on the course of RA. Nat. Rev. Rheumatol. 8 , 144-152 (2012).

14. Stastny, P. Mixed lymphocyte cultures in rheumatoid arthritis. J. Clin. Invest. 57, 1148-1157 (1976).

15. Raychaudhuri, S. et al. Five amino acids in three HLA proteins explain most of the association between MHC and seropositive rheumatoid arthritis. Nat. Genet. 44, 291-296 (2012).

16. Shadick, N. A. et al. Opposing effects of the D70 mutation and the shared epitope in HLA-DR4 on disease activity and certain disease phenotypes in rheumatoid arthritis. Ann. Rheum. Dis. 66, 1497-1502 (2007).

17. van der Woude, D. et al. Protection against anti-citrullinated protein antibodypositive rheumatoid arthritis is predominantly associated with HLADRB1 ${ }^{\star} 1301$ : a meta-analysis of HLA-DRB1 associations with anti-citrullinated protein antibody-positive and anti-citrullinated protein antibody-negative rheumatoid arthritis in four European populations. Arthritis Rheum. 62, 1236-1245 (2010).

18. Feitsma, A. L. et al. Protective effect of noninherited maternal HLA-DR antigens on rheumatoid arthritis development. Proc. Natl Acad. Sci. USA 104, 19966-19970 (2007).

19. Chicz, R. M. et al. Predominant naturally processed peptides bound to HLADR1 are derived from MHC-related molecules and are heterogeneous in size. Nature 358, 764-768 (1992).

20. Collado, J. A. et al. Composition of the HLA-DR-associated human thymus peptidome. Eur. J. Immunol. 43, 2273-2282 (2013).

21. Adamopoulou, E. et al. Exploring the MHC-peptide matrix of central tolerance in the human thymus. Nat. Commun. 4, 2039 (2013). 
22. Snijders, A. et al. An HLA-DRB1-derived peptide associated with protection against rheumatoid arthritis is naturally processed by human APCs. J. Immunol. 166, 4987-4993 (2001).

23. Romero, V. et al. Immune-mediated pore-forming pathways induce cellular hypercitrullination and generate citrullinated autoantigens in rheumatoid arthritis. Sci. Transl. Med. 5, 209ra150 (2013).

24. di Marzo Veronese, F. et al. Autoreactive cytotoxic T lymphocytes in human immunodeficiency virus type 1-infected subjects. J. Exp. Med. 183, 2509-2516 (1996).

25. Propato, A. et al. Apoptotic cells overexpress vinculin and induce vinculinspecific cytotoxic T cell cross-priming. Nat. Med. 7, 807-813 (2001).

26. Oldstone, M. B., Nerenberg, M., Southern, P., Price, J. \& Lewicki, H. Virus infection triggers insulin-dependent diabetes mellitus in a transgenic model: role of anti-self (virus) immune response. Cell 65, 319-331 (1991)

27. Wucherpfennig, K. W. \& Strominger, J. L. Molecular mimicry in T cellmediated autoimmunity: viral peptides activate human $\mathrm{T}$ cell clones specific for myelin basic protein. Cell 80, 695-705 (1995)

28. van de Stadt, L. A. et al. Monoclonal anti-citrullinated protein antibodies selected on citrullinated fibrinogen have distinct targets with different crossreactivity patterns. Rheumatology 52, 631-635 (2013).

29. Gregersen, P. K., Silver, J. \& Winchester, R. J. The shared epitope hypothesis. An approach to understanding the molecular genetics of susceptibility to rheumatoid arthritis. Arthritis Rheum. 30, 1205-1213 (1987)

30. de Vries, N., Tijssen, H., van Riel, P. L. \& van de Putte, L. B. Reshaping the shared epitope hypothesis: HLA-associated risk for rheumatoid arthritis is encoded by amino acid substitutions at positions 67-74 of the HLA-DRB1 molecule. Arthritis Rheum. 46, 921-928 (2002).

31. van der Helm-van Mil, A. H. et al. An independent role of protective HLA class II alleles in rheumatoid arthritis severity and susceptibility. Arthritis Rheum. 52, 2637-2644 (2005).

32. Shadick, N. A. et al. Opposing effects of the D70 mutation and the shared epitope in HLA-DR4 on disease activity and certain disease phenotypes in rheumatoid arthritis. Ann. Rheum. Dis. 66, 1497-1502 (2007).

33. Hensvold, H. A. et al. Environmental and genetic factors in the development of anticitrullinated protein antibodies (ACPAs) and ACPA-positive rheumatoid arthritis: an epidemiological investigation in twins. Ann. Rheum. Dis. 74, 375-380 (2013)

34. Enouz, S., Carrie, L., Merkler, D., Bevan, M. J. \& Zehn, D. Autoreactive T cells bypass negative selection and respond to self-antigen stimulation during infection. J. Exp. Med. 209, 1769-1779 (2012).

35. Hand, T. W. et al. Acute gastrointestinal infection induces long-lived microbiota-specific T cell responses. Science 337, 1553-1556 (2012).

36. Liu, X., Zou, Q., Zeng, B., Fang, Y. \& Wei, H. Analysis of fecal lactobacillus community structure in patients with early rheumatoid arthritis. Curr. Microbiol. 67, 170-176 (2013).

37. de Rooy, D. P., van der Linden, M. P., Knevel, R., Huizinga, T. W. \& van der Helm-van Mil, A. H. Predicting arthritis outcomes-what can be learned from the Leiden Early Arthritis Clinic? Rheumatology 50, 93-100 (2011).

38. Erlich, H., Lee, J. S., Petersen, J. W., Bugawan, T. \& DeMars, R. Molecular analysis of HLA class I and class II antigen loss mutants reveals a homozygous deleteion of the DR, DR, and part of the DP region: implications for class II gene order. Hum. Immunol. 16, 205-219 (1986).

39. Stepniak, D. et al. Large-scale characterization of natural ligands explains the unique gluten-binding properties of HLA-DQ2. J. Immunol. 180, 3268-3278 (2008).

40. Shi, J. et al. Autoantibodies recognizing carbamylated proteins are present in sera of patients with rheumatoid arthritis and predict joint damage. Proc. Natl Acad. Sci. USA 108, 17372-17377 (2011).

41. Moustakas, A. K. et al. Structure of celiac disease-associated HLA-DQ8 and non-associated HLA-DQ9 alleles in complex with two disease-specific epitopes. Int. Immunol. 12, 1157-1166 (2000).

42. Lee, K. H., Wucherpfennig, K. W. \& Wiley, D. C. Structure of a human insulin peptide-HLA-DQ8 complex and susceptibility to type 1 diabetes. Nat. Immunol. 2, 501-507 (2001).

43. Murthy, V. L. \& Stern, L. J. The class II MHC protein HLA-DR1 in complex with an endogenous peptide: implications for the structural basis of the specificity of peptide binding. Structure 5, 1385-1396 (1997).

44. Fremont, D. H., Hendrickson, W. A., Marrack, P. \& Kappler, J. Structures of an MHC class II molecule with covalently bound single peptides. Science 272, 1001-1004 (1996).

45. Rostkowski, M., Olsson, M. H., Sondergaard, C. R. \& Jensen, J. H. Graphica analysis of $\mathrm{pH}$-dependent properties of proteins predicted using PROPKA. BMC Struct. Biol. 11, 6 (2011).

46. Simonson, T. et al. Computational protein design: the Proteus software and selected applications. J. Comput. Chem. 34, 2472-2484 (2013).

47. Brooks, B. R. et al. CHARMM: the biomolecular simulation program. J. Comput. Chem. 30, 1545-1614 (2009).
48. Jo, S., Kim, T., Iyer, V. G. \& Im, W. CHARMM-GUI: a web-based graphical user interface for CHARMM. J. Comput. Chem. 29, 1859-1865 (2008).

49. MacKerell, A. D. et al. All-atom empirical potential for molecular modeling and dynamics studies of proteins. J. Phys. Chem. B 102, 3586-3616 (1998).

50. Mackerell, Jr. A. D., Feig, M. \& Brooks, III C. L. Extending the treatment of backbone energetics in protein force fields: limitations of gas-phase quantum mechanics in reproducing protein conformational distributions in molecular dynamics simulations. J. Comput. Chem. 25, 1400-1415 (2004).

51. Jorgensen, W. L., Chandrasekhar, J., Madura, J. D., Impey, R. W. \& Klein, M. L. Comparison of simple potential functions for simulating liquid water. J. Chem. Phys. 79, 926-935 (1983).

52. Neria, E., Fischer, S. \& Karplus, M. Simulation of activation free energies in molecular systems. J. Chem. Phys. 105, 1902-1921 (1996).

53. Darden, T., York, D. \& Pedersen, L. Particle Mesh Ewald: an N.Log(N) method for Ewald sums in large systems. J. Chem. Phys. 98, 10089-10092 (1993).

54. Nose, S. A. Unified formulation of the constant temperature moleculardynamics methods. J. Chem. Phys. 81, 511-519 (1984).

55. Hoover, W. G. Canonical dynamics - equilibrium phase-space distributions Phys. Rev. A 31, 1695-1697 (1985).

56. Feller, S. E., Zhang, Y. H., Pastor, R. W. \& Brooks, B. R. Constant-pressure molecular-dynamics simulation - the Langevin Piston method. J. Chem. Phys 103, 4613-4621 (1995).

57. Ryckaert, J. P., Ciccotti, G. \& Berendsen, H. J. C. Numerical-integration of cartesian equations of motion of a system with constraints - moleculardynamics of N-alkanes. J. Comput. Phys. 23, 327-341 (1977).

58. Humphrey, W., Dalke, A. \& Schulten, K. VMD: visual molecular dynamics. J. Mol. Graph. 14, 33-38 (1996).

59. Tamamis, P., Morikis, D., Floudas, C. A. \& Archontis, G. Species specificity of the complement inhibitor compstatin investigated by all-atom molecular dynamics simulations. Proteins 78, 2655-2667 (2010).

60. Tamamis, P. et al. Insights into the mechanism of C5aR inhibition by PMX53 via implicit solvent molecular dynamics simulations and docking. BMC Biophys. 7, 5 (2014).

61. Im, W., Lee, M. S. \& Brooks, III C. L. Generalized born model with a simple smoothing function. J. Comput. Chem. 24, 1691-1702 (2003).

62. Chen, J., Im, W. \& Brooks, III C. L. Balancing solvation and intramolecular interactions: toward a consistent generalized Born force field. J. Am. Chem. Soc. 128, 3728-3736 (2006)

\section{Acknowledgements}

We thank B. Malissen (Centre d'Immunologie de Marseille-Luminy, Université de la Méditerranée, Marseille, France) for providing us with the B8.11.2 hybridoma. The Silicon Graphics Fuel instrument and the accompanying software were obtained via a grant from the Epirus Regional Development Programme to the Epirus Institute of Technology, through the third Community Support Framework of the European Union (80\% European Union funds, $20 \%$ Hellenic state funds). This work was further supported by an NWO-ZonMW VICI grant from the Netherlands Organization for Scientific Research, by the IMI JU funded project BeTheCure, contract no 115142-2 and by a University of Cyprus grant to G.A. and S.P.

\section{Author contributions}

J.v.H. designed, performed and analysed the experiments and wrote the paper. D.T.S.L.J performed and analysed the experiments. A.K.M. and S.P. performed the modelling experiments. M.B., A.L.F. and D.G.B.-E. designed and performed the experiments. M.B performed experiments. D.v.d.W. helped with the manuscript and statistical analyses. G.-J.W. and T.R. designed the experiments with monoclonal ACPA. G.A. and G.K.P. were critically involved in designing the modelling experiments. F.K., R.R.P.d.V. and T.W.H. were critically involved in designing the experiments. R.E.T. helped design the experiments, analysed the experiments and helped to write the paper.

\section{Additional information}

Accession codes: The molecular models of DERAA peptides in complex with HLA-DQ molecules have been deposited in the Figshare repository under accession code 1294716 (http://dx.doi.org/10.6084/m9.figshare.1294716).

Supplementary Information accompanies this paper at http://www.nature.com/ naturecommunications

Competing financial interests: The authors declare no competing financial interests

Reprints and permission information is available online at http://npg.nature.com/ reprintsandpermissions/

How to cite this article: van Heemst, J. et al. Crossreactivity to vinculin and microbes provides a molecular basis for HLA-based protection against rheumatoid arthritis. Nat. Commun. 6:6681 doi: 10.1038/ncomms7681 (2015). 